\title{
Three-dimensional Structure of Microbial 2-Hydroxyl-6-oxo-6-phenylhexa- 2,4-dienoic Acid (HPDA) Hydrolase (BphD Enzyme) from Rhodococcus sp. Strain RHA1, in the PCB Degradation Pathway
}

\author{
By Narayanasamy Nandhagopal, ${ }^{*)}$ Toshiya Senda, ${ }^{*)}$ Takashi Hatta, ${ }^{* *}$ Akihiro Yamada, ${ }^{*)}$ \\ Eiji MASAI, ${ }^{*)}$ Masao FuKUdA, ${ }^{*)}$ and Yukio Mitsui*) \\ (Communicated by Setsuro EBASHI, M.J.A., Sept. 12, 1997)
}

\begin{abstract}
The three-dimensional structure of an enzyme, 2-hydroxyl-6-oxo-6-phenylhexa-2,4-dienoic acid (HPDA) hydrolase (conventionally called BphD) from Rhodococcus sp. strain RHA1 has been solved by Xray crystal structure analysis. This enzyme hydrolyzes one of the highly reactive intermediates, the meta cleavage product of the reaction catalyzed by 2,3-dihydroxybiphenyl dioxygenase, in the metabolic pathway degrading biphenyl compounds including the notorious environmental pollutant PCBs (polychlorinated biphenyls). By virtue of this and several other enzymes, the biphenyl compounds including PCBs are finally introduced into the tricarboxylic acid cycle. The BphD enzyme is an oligomeric enzyme made up of eight identical subunits each of 285 amino acid residues. The subunit consists of two domains, $\alpha / \beta$ domain and $\alpha$ domain, between which the active site is located.
\end{abstract}

Key words: $\mathrm{BphD}$; crystal structure; hydrolase; $\mathrm{PCB}$ degradation; $\alpha \beta$ hydrolase fold; protein structure.

Polychlorinated biphenyls (PCBs) are widely distributed environmental pollutants. Their thermal and chemical stability, which led to their widespread industrial use, have created a major problem in the disposal of these fat soluble, toxic xenobiotics. One of the most attractive means for their removal from the environment is the use of microbes (bioremediation). Since 1973, various microorganisms that could degrade biphenyl compounds including PCBs have been isolated and characterized. ${ }^{1-6)}$ In the metabolic pathway having the capacity for the oxidative degradation of PCBs leading to chlorobenzoates and 2hydroxypenta-2,4-dienoate, four specific enzymes are sequentially involved: biphenyl dioxygenase (named $\mathrm{BphA}$ ), dihydrodiol dehydrogenase (BphB), 2,3-dihydroxybiphenyl dioxygenase (BphC), and 2-hydroxyl-6-oxo-6phenylhexa-2,4-dienoic acid (HPDA) hydrolase (BphD).

The product of the $b p h D$ gene, $\mathrm{BphD}$, hydrolytically converts one of the highly reactive intermediates, the meta cleavage product (2-hydroxyl-6-oxo-6-phenylhexa-2,4-

*) Department of BioEngineering, Nagaoka University of Technology, Nagaoka, Niigata 940-21, Japan.

**) Research Institute of Technology, Okayama University of Science, Okayama 703, Japan. dienoic acid) of the reaction catalyzed by the preceeding enzyme BphC, into benzoic acid and 2-hydroxypenta-2,4dienoate or corresponding chlorinated compounds. These compounds are eventually converted into the intermediates of the central metabolism through the tricarboxylic acid cycle. This enzyme has close amino acid sequence homology with other corresponding hydrolases involved in the biodegradative pathways for aromatic compounds. The latter enzymes involve $d m p D, x y l \mathrm{~F}$, todF (2-hydroxyl-6oxohepta-2,4-dienoate hydrolase), and $b d o \mathrm{PO}$ respectively involved in the (phenol and dimethyl phenol), (xylene and toluene), toluene and benzene degradation pathways. In these sequences, a pentapeptide motif, $\mathrm{GlyX}_{1} \mathrm{Ser}_{2} \mathrm{Gly}$ ( $\mathrm{X}_{1}$ and $\mathrm{X}_{2}$ can be any amino acid), similar to the consensus "lipase box" $\mathrm{GlyX}_{1} \mathrm{Ser}_{2} \mathrm{Gly}$ which contains the catalytically essential Ser residue, ${ }^{7)}$ is commonly found. Thus, by analogy with lipases, the $\mathrm{BphD}$ enzyme may well involve a Ser-Asp(Glu)-His catalytic triad which has been well established in the cases of serine and cysteine proteinases. ${ }^{7), 8)}$ Apparently supporting this notion, the $\mathrm{BphD}$ enzyme is strongly inhibited by a serine protease inhibitor PMSF. The details, of course, had to await the elucidation of the three-dimensional structure of this 


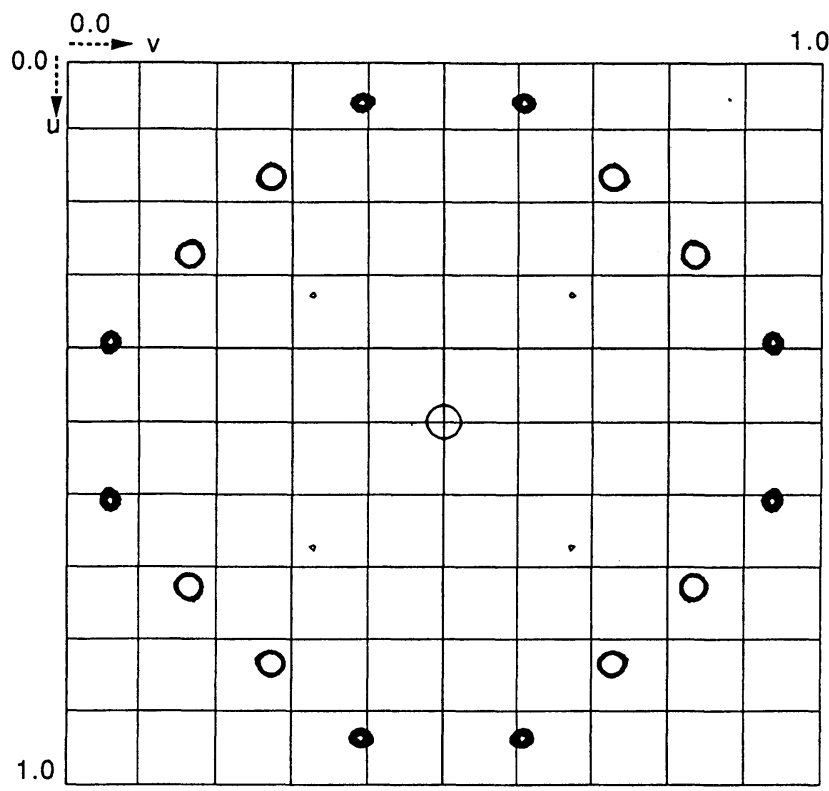

Fig. 1. The difference Patterson map calculated for the $\operatorname{Hg}(\mathrm{SCN})_{2}$ derivative showing one binding site for mercury atom. Harker section at $\mathrm{w}=0.5$.

enzyme, which is now reported here.

The BphD enzyme (an HPDA (2-hydroxyl-6-oxo-6phenylhexa-2,4-dienoic acid) hydrolase) from Rhodococcus sp. strain RHA1 is composed of eight identical subunits each of $c a .32 \mathrm{kDa}$ consisting of 285 amino acid residues. ${ }^{9)}$ The total molecular weight of the octameric enzyme is $c a$. $256 \mathrm{kDa}$. Interestingly some of the related enzymes have different subunit compositions. For example an HPDA hydrolase from $P$. pseudoalkaligenes KF707 is a tetramer, whereas the 2-hydroxyl-6-oxohepta-2,4-dienoate (HOHD) hydrolases from $P$. putida mt-2 and $P$. putida $\mathrm{F} 1$ are reported to be a dimer. ${ }^{10)}$ The HOHD (rather than HPDA as in the present study) hydrolase from Rhodococcus sp. strain RHA1 is also a dimer [Fukuda, M. et al., submitted]. Apparently, the subunit structures of these hydrolases do not reflect the distinct substrate specificity, but may reflect their evolutionary relationships.

We now report on the three-dimensional structure of the Rhodococcus RHA1 BphD enzyme (hereafter simply referred to as the $\mathrm{BphD}$ enzyme) as determined by X-ray crystal structure analysis. Crystallization of the $\mathrm{BphD}$ enzyme was carried out using the batch method as described elsewhere. ${ }^{11)}$ The space group is $I 422$ with cell dimensions $a=b=110.8 \AA, c=136.4 \AA$. Each asymmetric unit contains one subunit of the octameric molecule of the $\mathrm{BphD}$ enzyme. X-ray diffraction data for the native crystal was collected up to $2.5 \AA$ resolution. Derivative crystals were prepared by soaking method using the heavy atom compounds $\mathrm{Hg}(\mathrm{SCN})_{2}, \mathrm{KAu}(\mathrm{CN})_{2}$ or $\mathrm{K}_{2} \mathrm{PtCl}_{4}$. A series of data collection for these derivative crystals was performed at room temperature using Rigaku R-AXIS IIc area detector with $\mathrm{CuK} \alpha$ radiation (generated by a Rigaku RU200 rotating-anode generator operating at $4.95 \mathrm{~kW}$ and focused by a SUPPER double focusing mirror) at $2.5 \AA$ resolution. Using difference Patterson map (Fig. 1), the heavy atom position (one site for each subunit) for the mercury derivative was solved. The initial set of phases was calculated using this derivative and used for calculating cross difference Fourier maps which indicated the heavy atom positions for other derivatives. We have also prepared selenomethionyl-BphD derivative crystals ${ }^{12)}$ (Se$\mathrm{BphD}$ ) which was used as one of the derivatives. The heavy atom positions were refined by maximum likelihood refinement using the program MLPHARE in the CCP4 suite. ${ }^{14)}$ The phasing power for the $\mathrm{Hg}, \mathrm{Au}, \mathrm{Pt}$ and Se$\mathrm{BphD}$ derivatives were found to be $1.3,0.5,0.6$ and 0.75 respectively. With this phase set, we were able to calculate an interpretable electron density map. A portion of the electron density map calculated from the MIR phase is shown in Fig. 2. There are twelve methionine residues in each subunit of the $\mathrm{BphD}$ enzyme. The difference Fourier map between the Se-BphD and native $\mathrm{BphD}$ crystals showed 10 clear peaks presumably reflecting the (selenium-sulfur) electron density difference and thus indicating the locations of Met residues in the native protein. For the residual two Met positions we could not refine the positions of the Se atom as they had high temperature factors. The presence of the positional 


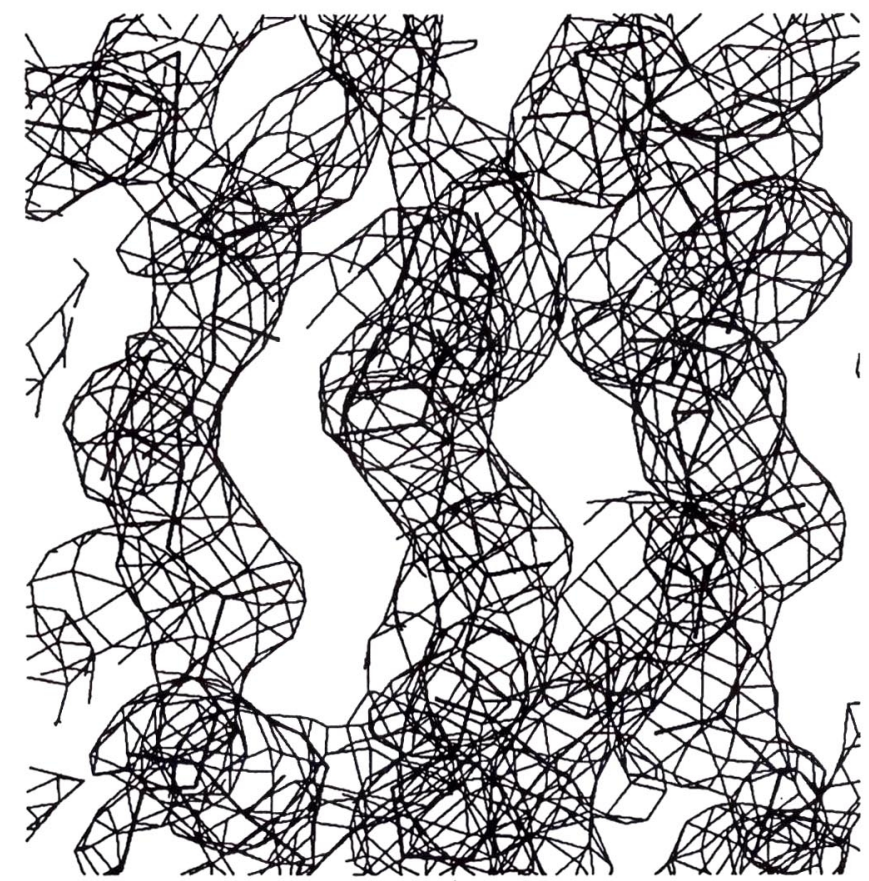

Fig. 2. Portion of the electron density map resulting from the MIR phase showing three $\beta$-strands.

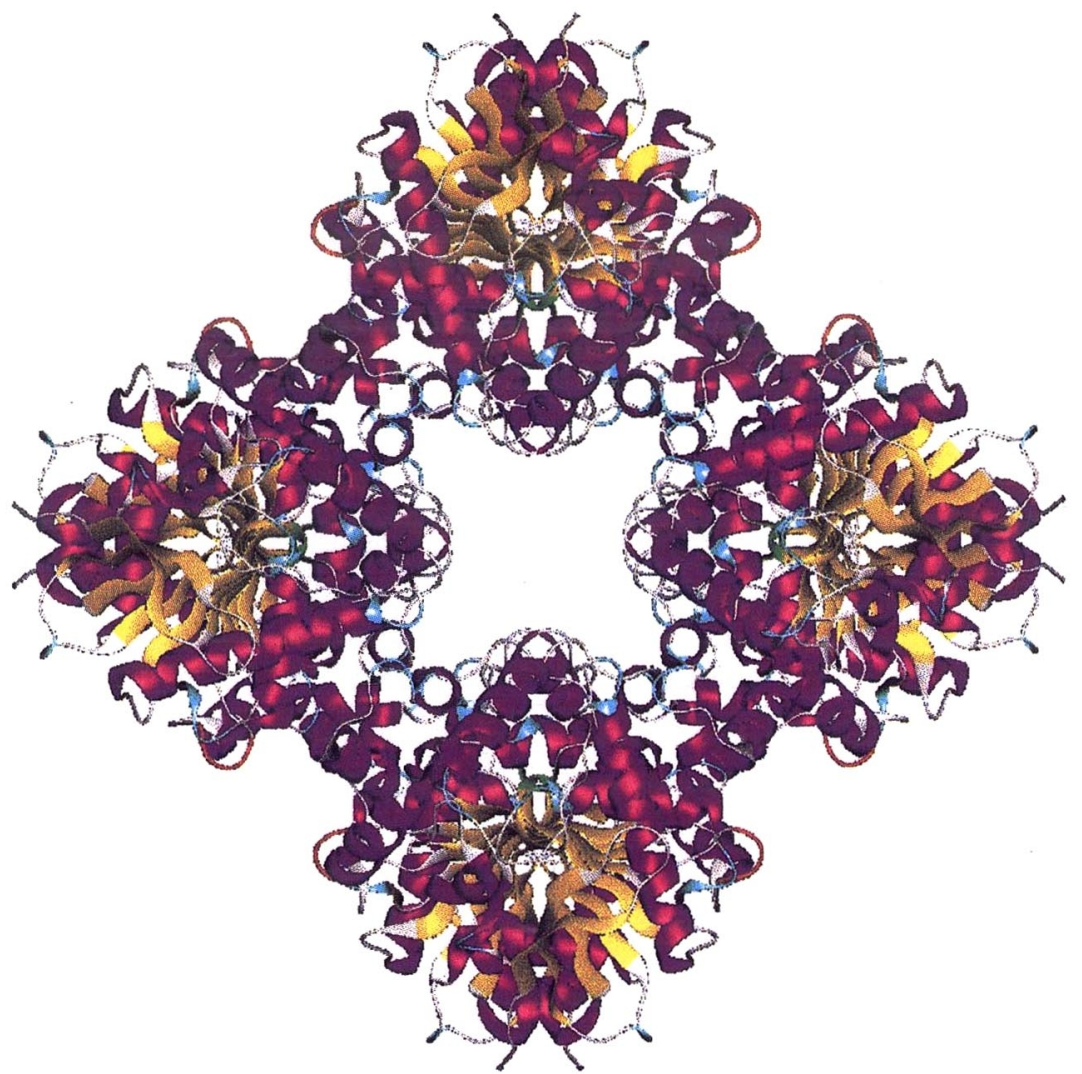

Fig. 3. Ribbon diagram of the octameric structure of the $\mathrm{BphD}$ enzyme viewed along the four fold axis. Because of extensive overlaps, the four subunits belonging to the lower layer are mostly invisible. 
markers for Met residues made possible a rapid interpretation of the electron density map in terms of the polypeptide chain fold. The overall structure was well determined except for the following three regions: Ala1 to Val4, Ala208 to Val214 and Trp 281 to Ala282. The refinement of the structure has been done using the programs XPLOR ${ }^{13)}$ and Refmac. ${ }^{14)}$ After a few cycles of refinement, current Rfactor is $23.5 \%$ (free $\mathrm{R}$-factor is $32.3 \%$ ) for 13,233 reflections in the 10.0-2.6 $\AA$ resolution range. The rootmean-square deviations from idealities were $0.02 \AA$ for bond lengths and $1.71^{\circ}$ for bond angles. Currently the model involves 2,134 non-hydrogen atoms with no water molecules yet assigned. Crystallographic details and the further refined structure will be reported elsewhere. The refined coordinates of the $\mathrm{BphD}$ enzyme will be deposited in the Brookhaven Protein Data Bank.

The octameric BphD enzyme has an overall dimension of $82 \AA$ along the four fold axis and $105 \AA$ along the two-fold axis running perpendicular to the four-fold axis. The overall structure can be regarded as a stack of two planar rings each of which consists of four subunits related by four-fold rotational symmetry. The octameric structure of the $\mathrm{BphD}$ enzyme is shown in Fig. 3. Across the two-fold axis perpendicular to the four-fold axis, the two $\beta$-sheets each consisting of eight $\beta$-strands from the adjoining subunits are united so as to form a single $\beta$-sheet consisting of sixteen $\beta$-strands.

The structure of the subunit of BphD enzyme may be classified into one of the $\alpha \beta$ hydrolase fold family proposed by Ollis $e t a l .{ }^{15)}$ The polypeptide chain fold of this enzyme is similar to those found in the crystal structures of haloalkane dehalogenase ${ }^{16)}$ and lipase ${ }^{17)}(\alpha \beta$ hydrolase fold family). Surprisingly these two enzymes exhibit no significant amino acid sequence homology with the BphD enzyme. The three-dimensional structure of the subunit of the BphD enzyme consists of two domains, $\alpha / \beta$ and $\alpha$ domains, between which the active site is located. In the $\alpha / \beta$-domain, there is an eight-stranded $\beta$-sheet in which the first three $\beta$-strands are arranged in an antiparallel fashion, while the residual five $\beta$-strands are arranged in a parallel fashion. In the eight-stranded $\beta$-sheet, the $\beta \alpha \beta$ motif, arranging the two $\beta$-strands parallel, repeatedly appear five times. In the $\alpha$-domain there are four $\alpha$ helices.

Now we are collecting high resolution data for the native crystal. We also plan to solve the structure of the complex of this enzyme with a serine protease inhibitor PMSF. The detailed analyses will give an insight into the catalytic role of this $\mathrm{BphD}$ enzyme in the $\mathrm{PCB}$ degradation pathway and also should give an idea as to the evolutionary relationship among the related hydrolases.

Acknowledgements. This study was supported in part by the TARA (Tsukuba Advanced Research Alliance) project.

\section{References}

1) Ahmed, M., and Focht, D. D. (1973) J. Microbiol. 19, 47-52.

2) Furukawa, K., Matumura, R., and Tonomura, K. (1978) Agric. Biol. Chem. 42, 543-548.

3) Furukawa, K. (1982) In the Biodegradation and Detoxification of Environmental Pollutants (ed. Boca Raton, F. L.). CRC Press, pp. 33-57.

4) Bedard, D. L., Unterman, R., Bopp, L. H., Brennan, M. J., Haberl, M. L., and Johnson, C. (1986) Appl. Environ. Microbiol. 51, 761-768.

5) Bedard, D. L., Wagner, R. E., Brennan, M. J., Haberl, M. L., and Brown J. F., Jr. (1987) Appl. Environ. Microbiol. 53, 1094-1102.

6) Kimbara, K., Hashimoto, T., Fukuda, M., Koana, T., Takagi, M., Oishi, M., and Yano, K. (1988) Agric. Biol. Chem. 52, 2885-2891.

7) Hofer, B., Eltis, L. D., Dowling, D. N., and Timmis, K. N. (1993) Gene 130, 47-55.

8) Ahmad, D., Fraser, J., Sylvertre, M., Larose, A., Khan, A., Bergeron, J., Juteau, J. M., and Sondossi, M. (1995) Gene 156, 69-74.

9) Masai, E., Sugiyama, K., Iwashita, N., Shimizu, S., Hauschild, J. E., Hatta, T., Kimbara, K., Yano, K., and Fukuda, M. (1997) Gene 187, 141-149.

10) Menn, F. M., Zylstra, G. J., and Gibson, D. T. (1991) Gene 104, 91-94.

11) Nandhagopal, N., Senda, T., Hatta, T., Yamada, A., Masai, E., Fukuda, M., and Mitsui, Y. (1997) Prot. and Pep. Lett. 4, 211-214.

12) Hendrickson, W. A., Horton, J. R., and LeMaster, D. M. (1990) EMBO J. 9, 1665-1672.

13) Brünger, A. T. (1992) X-PLOR, Version 3.1. A system for Xray Crystallography and NMR (New Haven, Connecticut: Yale University Press).

14) The CCP4 Suite: Programs for Protein Crystallography (1994) Acta Crystallogr. D50, 760-763.

15) Ollis, D. L., Cheah, E., Cygler, M., Dijkstra, B., Frolow, F., Franken, S. M., Harel, M., Remington, S. J., Silman, I., Schrag, J., Sussman, J. L., Vershueren, K. H. G., and Goldman, A. (1992) Protein Eng. 5, 197-211.

16) Franken, S. M., Rozeboom, H. J., Kalk, K. H., and Dijkstra, B. W. (1991) EMBO J. 10, 1297-1302.

17) Schrag, J. D., Li, Y., Cygler, M., Lang, D., Burgdorf, T., Hecht, H-J., Schmid, R., Schomburg, D., Rydel, T. J., Oliver, J. D., Strickland, L. C., Dunaway, C. M., Larson, S. B., Day. J., and McPherson, A. (1997) Structure 5, 187-202. 